\title{
Evaluation of Combined Sewage Trunk System (East Bank Trunk) in Al-Rusafa Area, Baghdad City, Iraq
}

\author{
Faris Hammodi Al-Ani, Sataa A.F. Al- Bayati and, Ali N. Jasim* \\ Building and Construction Engineering Department, University of Technology, Baghdad, Iraq
}

\begin{abstract}
This study came because of problems that recently occurred in the sewerage trunk in Baghdad city. In Rusafa, there are two main trunks (East Bank Trunk and Zublin Trunk) for the carry of sewage to the wastewater treatment plant in Rustamiyaha, some parts of Baghdad city were flooded due to high rainfall intensity in year 2013 and 2014 during winter for several days, the results obtained from the analysis showed that the design capacity of the transmission trunk of Baghdad does not meet the maximum operating conditions. It was also found that the hydraulic gradient is very low, which made the flow velocity less than the minimum recommended Self-cleansing velocity. This caused the deposition of particles that cause the blockage of the transmission main trunks.
\end{abstract}

Keywords: East Bank Trunk, Discharge of wastewater, Self-cleansing velocity

\section{Introduction}

Sanitary sewer systems are composed of piping that is used to transport wastewater consisting of residential, commercial, and industrial waste. Some amount of storm water, surface water, and groundwater may also be present in sanitary sewer systems.

Storm sewer systems are composed of those piping systems that carry only storm water, surface water, and other waters that are drained into the storm sewer system. They do not carry residential, commercial, or industrial wastes [7].

A combined sewer system consists of a combination of a sanitary sewer system and a storm sewer system. Thus, a combined sewer system carries both storm water as well as wastewater. Many existing sewer systems collect both wastewater and stormwater. In such systems, stormwater, up to a design limit, is channeled with sanitary wastewater to the treatment plant. When combined flow exceeds the sewer's capacity, combined sewer overflows (CSOs) occur and wastewater, along with stormwater, is discharged to receiving waters. When stormwater is transported with wastewater to the treatment plant, pumping and treatment costs are increased and treatment problems may occur. Combined sewer systems are no longer designed except as limited extensions or replacements for existing combined systems [1].

Studies by the U.S. Public Health Service (USPHS 1964) and the U.S. Environmental Protection Agency [5] show that combined stormwater and wastewater overflows introduce large quantities of polluting materials into the nation's waters. As a result of these issues and other concerns, the EPA in 1994 adopted a CSO control policy [12]. This policy includes minimum controls that sharply limit the use of combined sewer systems and essentially preclude their use in new construction.

Sewer systems are generally designed as gravity flow systems with a free water surface [9]. This means that the sewer pipe may run full or partially full so that there is an air space above the water level. This is known as openchannel flow. The advantage of open-channel flow includes ventilation of the sewer and maintenance of good velocities at low flow rates for cleaning the sewers. Pumps are also used to provide the lift necessary from deep sewer locations to force the sewage to a higher elevation from which point gravity flow can continue [9].

In general terms, older networks in urban area which have been based upon water courses culverted during urban development end to be on the combined system, while new networks are more commonly designed on the separate systems [8]. The design of sewers tends to be based upon minimum gradients and velocities to minimize excavation and number of pumping Stations. With a conventional design of combined system therefore self-cleansing velocities may only be reached once per day or at worst during the winter months only storm conditions. From this point of view therefore, a separate system is to be preferred [8].

Manholes are structures installed in gravity sewers to provide access for repairing, maintenance and cleaning of

*Corresponding author: alinaeem46@gmail.com 




Fig. 1. Baghdad Map

the sewer line. Typical cleaning equipment are 90-150 meters long, which naturally causes limiting factors for manhole spacing. Typically, no manholes should be placed approximately over 120 meters apart in straight runs of pipe [10].

Lift stations are needed because there are limitations how deep one can install the pipe in. When this point is reached, the water must be pumped to a higher altitude to proceed with the gravitational flow [4]. These facilities that do the pumping are called the pumping/lift stations. Common components found in pumping stations include: pumps (centrifugal pumps, pneumatic ejectors or screw pumps), hardware, bar racks, valves, electrical system, alarms, motor control center, hour recorders and pump controls [13]. Lift stations are subject to mechanical and electrical failures due to many components involved [6].

\section{Study Area}

Flows to the existing sewer works at Rustamiyaha rise primarily from the existing (East Bank Trunk) Sewer network which at present serve a total area of 5300 hectares 3600 ha.net. Its catchment area includes the central area between the Army canal and Tigris River, and the Karada. There are two main sewer trunks in al-Rusafa

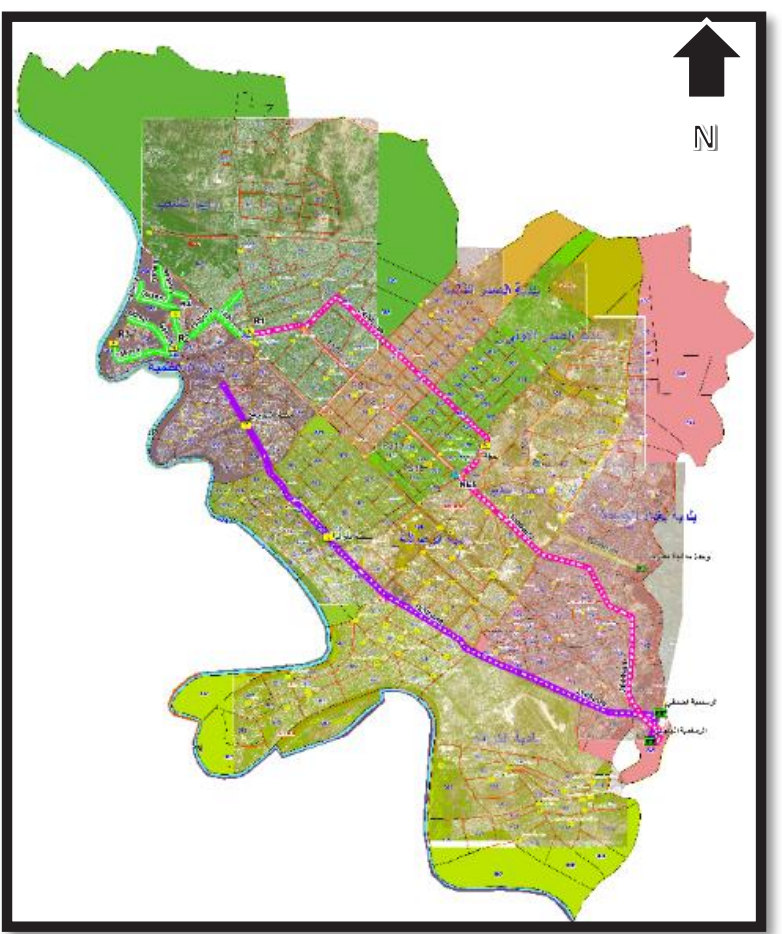

Fig. 2. Municipalities of Baghdad Rusafa Side [2] 
side/ Baghdad (East Trunk Sewer System (ET) and Zublin Trunk). ET trunk served (Al-Adamiah, Al-Rusafa center, Part of Al- Gadeer, Al-Karada, Part of Baghdad Al Jadidah) Municipalities.

The East Trunk sewer commences at manhole ET 139 in $760 \mathrm{~mm}$ dia. pipe increasing to $1100 \mathrm{~mm}$ dia. At Wazariyah pumping Station the diameter increases from $1100 \mathrm{~mm}$ to $1600 \mathrm{~mm}$. from Ghazali Pumping Station to the junction with Karrada submain trunk at ET 44 the diameter is $1850 \mathrm{~mm}$. from ET 44 to the sewage treatment works the diameter increases from 2150 to $2300 \mathrm{~mm}$ in terminal section [2]. The east trunk sewer is likely to be overloaded at future design flows in its lower lengths allowing for the sewerage of any mashing smaller areas within its existing catchment; It is therefore recommended that no further major areas should be connected [8].

\section{Methodology}

Data Collection: The data collected from municipalities sewage department, these Data include profiles of line (East trunk bank), maps that show municipalities zones and pump stations within areas served and discharge of these Pump Stations.

Data Analysis: The Manning equation is widely used and is one of the best open-channel hydraulics equations. Over time, it has largely replaced the Chézy and Kutter equations in engineering practice because of its relative simplicity. [9]. The value of roughness coefficient use, which depends on the type and internal condition of the pipe [1]. For older sewer pipes, a value of 0.015 may be used [9]. The general form of the Manning equation for open-channel flow is as follows:

$$
v=\frac{1}{n} R^{2 / 3} S^{1 / 2}
$$

where

- $\mathrm{V}=$ average velocity of flow, $\mathrm{m} / \mathrm{s}$

- $\mathrm{n}=$ roughness coefficient, dimensionless

- $\quad \mathrm{R}=$ hydraulic radius $=$ (wetted cross-sectional area/ wetted perimeter), $\mathrm{m}$ [for a circular pipe flowing full) $R=D / 4$

- $\mathrm{S}=$ slope of hydraulic energy gradient, $\mathrm{m} / \mathrm{m}$

The general form of the Manning equation for circular pipe flow is as follows:

$$
Q=\frac{0.312}{n} D^{8 / 3} S^{1 / 2}
$$

where

- $\mathrm{Q}=$ flow rate, $\mathrm{m} 3 / \mathrm{s}$

- $\mathrm{n}=$ roughness coefficient, dimensionless

- $\quad \mathrm{D}=$ inside diameter of pipe, $\mathrm{m}$

- $\mathrm{S}=$ slope of hydraulic energy gradient, $\mathrm{m} / \mathrm{m}$

Self-Cleansing Velocity: Since sanitary sewers contain suspended solids that may deposit on the pipe wall, some minimum velocity is desirable to keep the solid particles suspended and in motion. This velocity that is necessary to prevent deposition of solids is known as the self-cleansing velocity. When a sanitary sewer system is flowing full, minimum velocities range from $(0.6$ to $0.75 \mathrm{~m} / \mathrm{s}$ ). Storm sewers generally have a minimum velocity range of (1.0 to $1.2 \mathrm{~m} / \mathrm{s})$ [11]. The velocity of flow ensures the solids will remain in suspension and move with the water. There is also a maximum velocity that must not be exceeded to prevent erosion of the sewer pipe. The maximum velocity is in the range of ( 3 to 3.5 $\mathrm{m} / \mathrm{s}$ ) for both sanitary sewers and storm sewers [9].

The flow from pump stations calculated as flowrate from final pump station that connected with ET line and $60 \%$ as efficiency [3].

Capacity requirements determine the sewer slope, often sanitary sewers through 15 inches $(375 \mathrm{~mm})$ in diameter are designed to flow half-full. Larger sanitary sewers have been typically designed to flow threequarters full [1]. Hence, Calculate the Y/D ratio by using figure That Should be equal to $75 \%$ for Diameter Larger than $700 \mathrm{~mm}$ [11].

Represent the Data calculation in figure 3 to Show the variation of Sanitary Load through the Sections and figure 4 to show variation of flow velocity.

Table 1. Data Calculations; $M H$ : manhole, $\mathrm{D}(\mathrm{m})$ : diameter,

\begin{tabular}{|c|c|c|c|c|}
\hline sections & $\mathrm{MH}$ & $\mathrm{D}(\mathrm{m})$ & Qa $(I / s)$ & P.S \\
\hline 1 & ET139-ET135 & 0.76 & 147.6 & Al jawazat (322) \\
\hline \multirow{2}{*}{2} & \multirow{2}{*}{ ET134-ET118 } & 0.84 & 114 & Al-Shamasia (318) \\
\hline & & 0.84 & 127.2 & Aswaq Zohair (316) \\
\hline \multirow{3}{*}{3} & \multirow{3}{*}{ ET118-ET96 } & 1.10 & 33 & Al Moror Al Sarie (307) \\
\hline & & 1.10 & 612 & Al Mojama Al IImi (304) \\
\hline & & 1.10 & 66 & Al Waziriah Buildings (305) \\
\hline \multirow{4}{*}{4} & \multirow{4}{*}{ ET96-ET88 } & 1.30 & 114 & Al Sinaa (303) \\
\hline & & 1.30 & 81.6 & Al Muror (301) \\
\hline & & 1.30 & 99.96 & 5B (147) \\
\hline & & 1.30 & 16.8 & Bueeot Al-Ama (137) \\
\hline \multirow{4}{*}{5} & \multirow{4}{*}{ ET88-ET71 } & 1.60 & 99.96 & Birute (503) \\
\hline & & 1.60 & 15 & Al-Sekak (503) \\
\hline & & 1.60 & 19.8 & 135 \\
\hline & & 1.60 & 1500 & Al Gazali (135) \\
\hline \multirow{12}{*}{6} & \multirow{12}{*}{ ET71-ET44 } & 1.85 & 16.8 & AL-Maardh/1 (147) \\
\hline & & 1.85 & 16.8 & Al-Jumlla Al-Asabia (105) \\
\hline & & 1.85 & 30 & $8 B(103)$ \\
\hline & & 1.85 & 30 & $9 \mathrm{~A}(101)$ \\
\hline & & 1.85 & 58.2 & (702) وب \\
\hline & & 1.85 & 50.4 & Al-Qaser Al-Abeeadh (103) \\
\hline & & 1.85 & 27.6 & $702(702)$ \\
\hline & & 1.85 & 37.8 & $10 \mathrm{~B}(103)$ \\
\hline & & 1.85 & 50.4 & $27(708)$ \\
\hline & & 1.85 & 30 & $11(904)$ \\
\hline & & 1.85 & 37.8 & $12(906)$ \\
\hline & & 2.15 & 414 & Al-Hindiah (903)+14 B (409)+13 (904) \\
\hline \multirow{7}{*}{7} & \multirow{7}{*}{ ET44-ET1 } & 2.15 & 177.6 & Zaiona 3 + Zaiona 2+Sommer (704) \\
\hline & & 2.30 & 216 & $16 \mathrm{~B}(910)$ \\
\hline & & 2.30 & 10.8 & 701 \\
\hline & & 2.30 & 99.6 & Arafa (701) \\
\hline & & 2.30 & 241.8 & Pepsi +No. 3 (703) \\
\hline & & 2.30 & 6.6 & 713 \\
\hline & & 2.30 & 399.6 & SE 1 (954) \\
\hline
\end{tabular}
$\mathrm{Qa}(1 / \mathrm{s})$ : actual flow rate (from P.S)[2]. 


\section{Results and Discussions}

The ET line (East Bank Trunk) was analyzed by using the Manning equation for the design discharge (full flow rate) calculation according to the pipe diameters (D) and the hydraulic gradient $(\mathrm{S})$ using $\mathrm{n}=0.015$, depending on the operational conditions from the pumping stations including the number of pumps operated and the discharge of each pump with the efficiency of the pump $60 \%$. The result of analysis shows the ability of (East Bank Trunk) to quantity of discharge incoming from pumping stations (assuming there are no sediments) except the end of section 7 overflow appearance at ET7 from SE1 pump station that served Al- Zafarania city from Karada Municipal as shown in Table (1).

The Y/D ratio should not exceed $75 \%$ in large diameter, The Figure (3) shows this ratio during the sections and shows that some stations have exceeded this $75 \%$ as in Aswaq Zohair (316) (section 2), Al Waziriah Buildings (305) (section 3) in Al-Adhamiha Maniciple,5B (147) (section 4) in Rusafa Municipal, Arafa (701),Pepsi +No. 3 (703) (section 7) in Baghdad al-Jadidah municipal and finally SE 1 (954) (section 7) in Al-Karada municipal.

Table 2. Results : $\mathrm{MH}$ : manhole $\mathrm{Qt}(\mathrm{l} / \mathrm{s})$ :total flow rate , $\mathrm{Qd}(1 / \mathrm{s})$ : design flow rate, $\mathrm{V}(\mathrm{m} / \mathrm{s})$ : flow velocity, $75 \%$ :

\begin{tabular}{|c|c|c|c|c|c|c|c|}
\hline sections & $\mathrm{MH}$ & Qt (l/s) & Qd (I/s) & $\mathrm{V}(\mathrm{m} / \mathrm{s})$ & QT/QD \% & $75 \%$ & $\mathrm{Y} / \mathrm{D}$ \\
\hline 1 & ET139-ET135 & 147.6 & 340.41 & 0.32 & 43 & 75 & 46 \\
\hline \multirow{2}{*}{2} & \multirow{2}{*}{ ET134-ET118 } & 261.6 & 412.92 & 0.47 & 63 & 75 & 58 \\
\hline & & 388.8 & 412.92 & 0.70 & 94 & 75 & 77 \\
\hline \multirow{3}{*}{3} & \multirow{3}{*}{ ET118-ET96 } & 421.8 & 775.93 & 0.44 & 54 & 75 & 53 \\
\hline & & 612 & 725.81 & 0.64 & 84 & 75 & 70 \\
\hline & & 678 & 725.81 & 0.71 & 93 & 75 & 77 \\
\hline \multirow{4}{*}{4} & \multirow{4}{*}{ ET96-ET88 } & 792 & 981.35 & 0.60 & 81 & 75 & 68 \\
\hline & & 873.6 & 981.35 & 0.66 & 89 & 75 & 73 \\
\hline & & 973.56 & 981.35 & 0.73 & 99 & 75 & 81 \\
\hline & & 990.36 & 1365.79 & 0.49 & 73 & 75 & 63 \\
\hline \multirow{4}{*}{5} & \multirow{4}{*}{ ET88-ET71 } & 1090.32 & 1527.00 & 0.54 & 71 & 75 & 62 \\
\hline & & 1105.32 & 1763.23 & 0.55 & 63 & 75 & 57 \\
\hline & & 1125.12 & 1763.23 & 0.56 & 64 & 75 & 58 \\
\hline & & 1500 & 2097.15 & 0.56 & 72 & 75 & 63 \\
\hline \multirow{12}{*}{6} & \multirow{12}{*}{ ET71-ET44 } & 1516.8 & 2097.15 & 0.56 & 72 & 75 & 63 \\
\hline & & 1533.6 & 2169.07 & 0.57 & 71 & 75 & 62 \\
\hline & & 1563.6 & 2169.07 & 0.58 & 72 & 75 & 63 \\
\hline & & 1593.6 & 2169.07 & 0.59 & 73 & 75 & 64 \\
\hline & & 1651.8 & 2169.07 & 0.61 & 76 & 75 & 65 \\
\hline & & 1702.2 & 2169.07 & 0.63 & 78 & 75 & 67 \\
\hline & & 1729.8 & 2169.07 & 0.64 & 80 & 75 & 67 \\
\hline & & 1767.6 & 2338.33 & 0.66 & 76 & 75 & 65 \\
\hline & & 1818 & 2338.33 & 0.68 & 78 & 75 & 66 \\
\hline & & 1848 & 2418.07 & 0.69 & 76 & 75 & 65 \\
\hline & & 1885.8 & 2514.39 & 0.70 & 75 & 75 & 65 \\
\hline & & 2299.8 & 2837.65 & 0.63 & 81 & 75 & 68 \\
\hline \multirow{7}{*}{7} & \multirow{7}{*}{ ET44-ET1 } & 2477.4 & 2837.65 & 0.68 & 87 & 75 & 72 \\
\hline & & 2693.4 & 3177.37 & 0.65 & 85 & 75 & 71 \\
\hline & & 2704.2 & 3177.37 & 0.65 & 85 & 75 & 71 \\
\hline & & 2803.8 & 3177.37 & 0.68 & 88 & 75 & 73 \\
\hline & & 3045.6 & 3177.37 & 0.73 & 96 & 75 & 78 \\
\hline & & 3052.2 & 3177.37 & 0.74 & 96 & 75 & 79 \\
\hline & & 3451.8 & 3177.37 & 0.83 & 109 & 75 & 100 \\
\hline
\end{tabular}

Figure (4) shows the flow velocity through (East Bank Trunk) compared to the minimum self-cleaning velocity that shows the velocities are less than minimum self- cleaning velocity leading to cause sedimentation of particles.

\section{Conclusion}

The ET trunk has low slope that caused low self-cleaning velocity in trunk leading to sedimentation of particles and discharge of more than the design capacity of trunk during extreme conditions. 


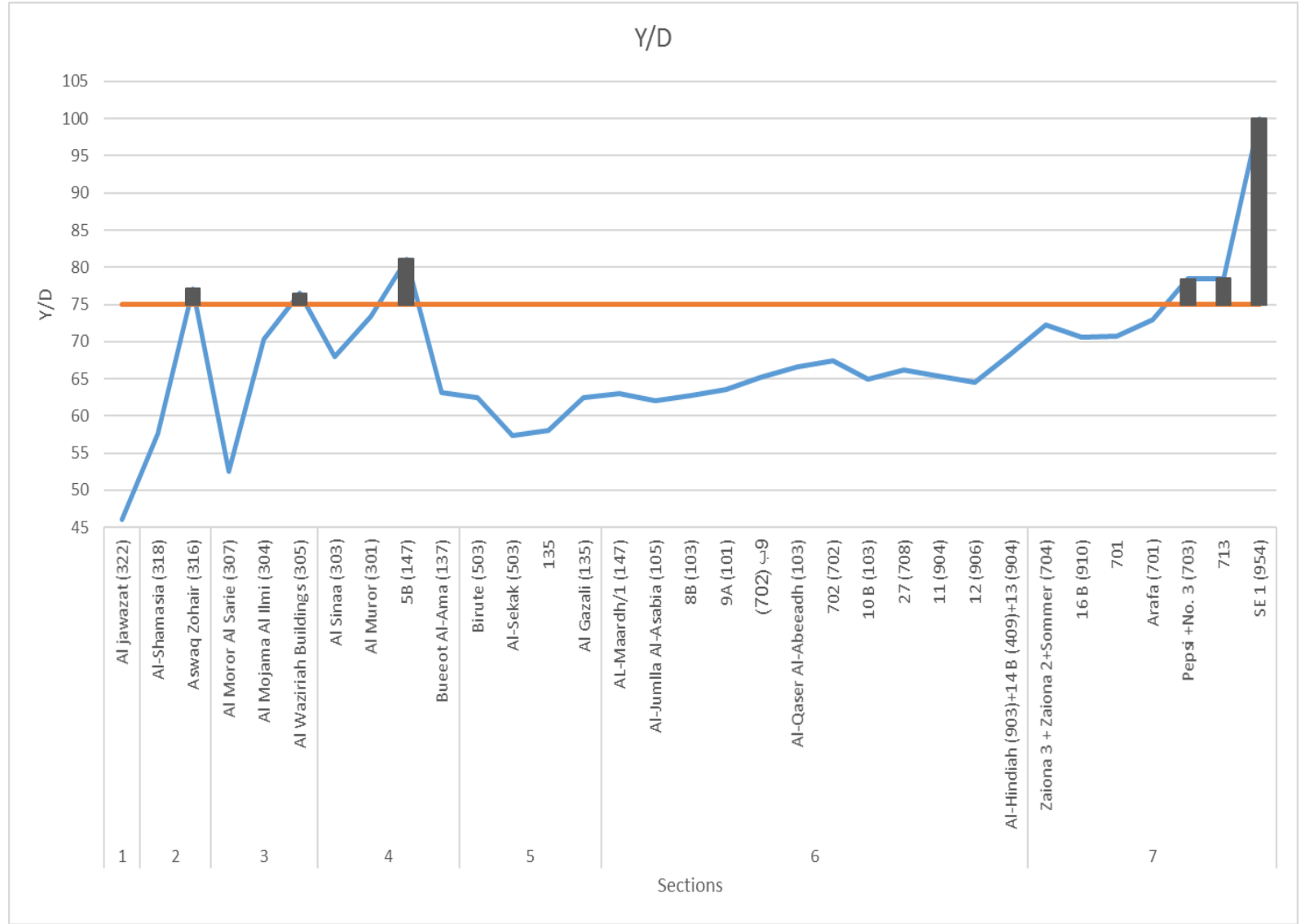

Fig. 3. Total flow rate compared with $75 \%$ Y/D ratio

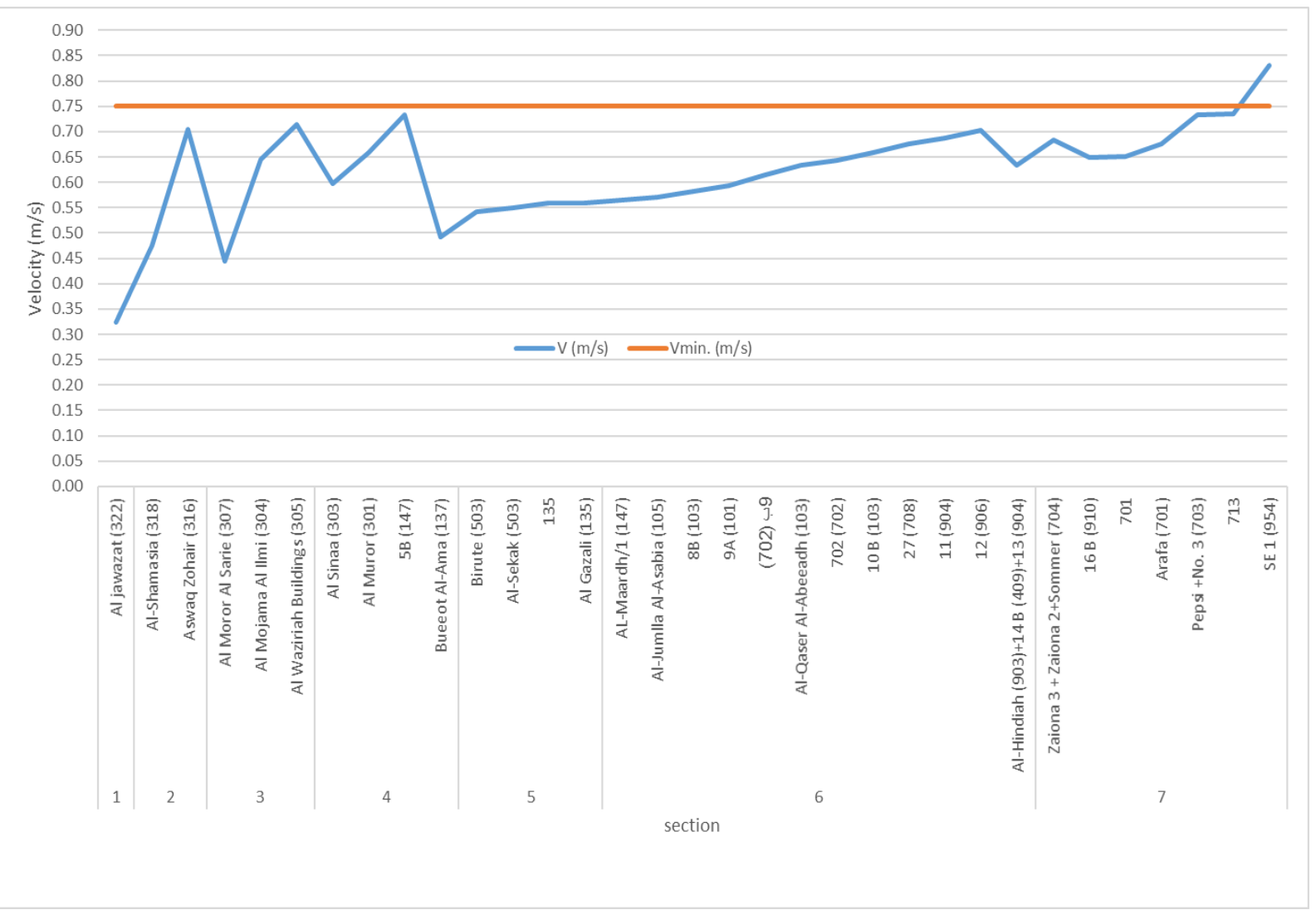

Fig. 4. Flow velocities with minimum self-cleaning velocity 


\section{References}

1. American Society of Civil Engineers (ASCE) “Gravity sewer design and construction. "2nd Edition (1982).

2. Baghdad Mayoralty, Design department (2016)

3. Baghdad Mayoralty, Pump Station department (P.S), workers . (2016)

4. J.R.. Buchanan, Cost of Decentralized Unit Processes. pp. 45-55 (2010). Available at: http://ndwrcdp.werf.org/documents/DEC2R08/DEC 2R08web.pdf.

5. Corporation Central Engineering Laboratories. A Flushing System for Combined Sewer Cleansing, 11020DNO03/72, NTIS PB 219 858, U.S. Environmental Protection Agency, Office of Research and Monitoring, Washington,D.C. (1970)

6. M.J.. Delzingaro There's No Use Crying Over Spilled Sewage: Using Standby Lift Station Pumps to Prevent SSOs before They Happen. pp. 1-3 (2006). Available at: http://www.environmentalexpert.com/Files\%5C530 6\%5Carticles $\% 5$ C8984\%5C168.pdf.

7. R. H. French, "Hydraulics of open channel flow." Stormwater collection systems design handbook, L. W. Mays, ed., McGraw-Hill, New York, with permission. (2001)

8. Haiste and Partiners. Greater Baghdad Sewerage Study. Volume 1 (1981)

9. Menon, E. Shashi. "Piping Calculations Manual" New York, McGraw-Hill (2005)

10. F. Ragsdale (n.d.). "Wastewater System Operator's Manual". Chapter 13. Available at: http://www.ragsdaleandassociates.com/js2524/index .php/tmat/wastewater-systemoperator-s-manual.

11. E.W. Steel, \& T.J. McGhee, " water supply \& sewerage", 5th Ed., McGraw-Hill (1979)

12. U.S. EPA (n.d.). Combined Sewer Overflow (CSO). pp. 2-6. Available at: http://www.epa.gov/nrmrl/wswrd/wq/stormwater/cs o.pdf.

13. WUTAP. Wastewater Systems Operator Certification Study Manual (2007). Available at: http://www.nmrwa.org/sites/nmrwa.org/files/Waste waterOperatorStudyManual.pdf. 